\title{
Profile of Medicolegal Autopsies Conducted at Bundelkhand Medical College, Sagar (M.P.)
}

\author{
Shailendra Patel ${ }^{1}$, Jitendra Singh Tomar², Ankit Pandey Jain ${ }^{3}$, Poornima Patel ${ }^{4}$ \\ ${ }^{I}$ Assistant Professor, Department of Forensic Medicine and Toxicology, Bundelkhand Medical College, Sagar \\ (M.P), ${ }^{2}$ Assistant Professor, Department of Forensic Medicine and Toxicology, MGM Medical College, Indore \\ (M.P), ${ }^{3} P G$ Resident, Department of Forensic Medicine and Toxicology, MGM Medical College, Indore (M.P), \\ ${ }^{4}$ Dental Surgeon at Aashirwad Dental Clinic, Sagar
}

\begin{abstract}
Death of humans is often investigated for the causes, in case of crime (such as Murder), accident or disease that may continue to kill other humans. Deathoccurs due to natural causes or unnatural causes. The study of profile of medicolegal autopsies help us in determining crime rate, accident and common diseases in that particular area and also helpful in preventing unnatural deaths, improving healthcare system and reflecting law and order situation of that area. The present study was based on retrospective analysis of the autopsies performed during the period of January 2018 to December 2018 in the Department of Forensic Medicine and Toxicology, Bundelkhand Medical College, Sagar (M.P).A total of 349 autopsies were conducted during this study period, of which majority of victims were male 195 (56\%) cases. Age group of 21-30 years having maximum number i.e. $128(36.7 \%)$ cases. Natural death accounted for $12(3.4 \%)$ cases and unnatural death $323(92.5 \%)$ cases. The major cause of death among unnatural deaths was burn in $116(33.23 \%)$ cases, followed byroad traffic accident (RTA) in 106 (30.37\%) cases and poisoning in 40 (11.46\%) cases. Burn was the major cause of death in our study, this may be due to smoking, defective electrical wiring, defective kerosene stove bursts, attempted suicides by self-immolation, homicidal burns of young women by husband or in-laws (dowry deaths).
\end{abstract}

Keywords: Burn, RTA, Poisoning, Natural Death, Unnatural death, Homicidal.

\section{Introduction}

India is a vast country with great diversities and regional variation among its population in their living, culture, festivals, food habits and other daily livelihood and this regional variation may affect the death trends. ${ }^{[1]}$ So the mortality pattern is different in different region of India. The pattern of mortality is a key indicator of the consequent health effects. ${ }^{[2]}$

\section{Corresponding Author: \\ Poornima Patel}

Dental Surgeon at Aashirwad Dental Clinic, Sagar

e-mail: poornimapatel38@gmail.com
In our modern society, RTA among males and burn among females are the major causes of death in different regions. NCRB data shows 4,45,514 RTA cases in 2018 , of these deaths occurred in 1,52,780 cases. Major cause of death in RTA is due to over speeding (55.2\%) followed by careless driving or overtaking (27.3\%) during 2018. ${ }^{[3]}$ In India, every year 1000000 people are moderately or severely injured due to burn injury. An estimated 180000 deaths every year are caused by burn and among those, vast majority occur in low and middleincome countries. ${ }^{[4]}$

Autopsy ensures to establish the identity of the body if unknown,to ascertain the time since death and the cause of death,to find out the manner of death, whether it was homicidal, suicidal or accidental. In case of new born infants, the question of live birth, viability and cause of death assume importance and 
should be determined. ${ }^{[5]}$ The objective of present study is to describe the distribution of autopsies on the basis of basic parameter such as age, sex, months, manner of death and cause of death.

\section{Materials and Methodology}

The present study is a retrospective study carried out in the department of Forensic Medicine \& Toxicology, Bundelkhand Medical College, Sagar (M.P). A total of 349 autopsies performed during the period of Jan 2018 to Dec 2018 were analysed. The data was collected from inquest record, medical record and post-mortem reports. Various parameters like age, sex, month, religion, manner and cause of death were taken into consideration. The information was compiled, tabulated and analysed.

\section{Results}

In a study period of one year, total 349 autopsies were conducted from $1^{\text {st }}$ Jan 2018 to $31^{\text {st }}$ Dec 2018 . Out of which, 195 (56\%) cases were male and 154 (44\%) cases were female having female: male ratio of 1:1.26.

\section{(Graph 1).}

On the basis of age group, maximum number of males belonged to the age group of 21-30 i.e. 64 (18.33\%) cases followed by age group of $31-40$ years with $33(9.45 \%)$ cases. In females $21-30$ age group had maximum number of cases i.e. $64(18.33 \%)$ cases followed by the 11-20 years age group with 34 (9.74\%) cases. Taking overall population into consideration 21-30 years age group had maximum number of cases i.e. $128(36.7 \%)$ cases. Number of males and females were same in the age group of 21-30 years i.e. 64 cases. Female number was dominating over male number in age group of 11-20 years i.e. 34 out of 60 cases and 7180 years i.e. 02 out of 03 cases. (Table no. 1).

In the present study,maximum autopsies were conducted in month of April with 41 (11.74\%) cases,followed by $40(11.46 \%)$ cases in the month of May. Month of November showed the least number of cases i.e. 17 cases $(4.87 \%)$. Deaths of females were more compared to males in the month of July i.e. 15 out of 28 cases and November i.e. 11 out of 17 cases. (Table no. 2)

Out of the total 349 cases, the cause of death was determined in $335(96 \%)$ cases. Out of these 335 cases, in $12(3.4 \%)$ cases the cause of death was natural, whereas in $323(92.5 \%)$ cases it was unnatural. The cause of death could not be determined in $14(4 \%)$ cases. (Figure 2). Out of 323 unnatural deaths, manner of death was accidental in $263(81.4 \%)$ cases, suicidal in $57(17.6 \%)$ cases and homicidal in 03 (1\%) cases. (Figure 3).

Distribution of cases according to cause of death showed that maximum number of deaths were due to burn i.e. $116(33.23 \%)$ followed by death due to RTA in $106(30.37 \%)$ cases, poisoning in $40(11.46 \%)$ cases and snakebite in $21(6.01 \%)$ cases. The least number of deaths were observed in case of assault, gunshot, blast Injuries and cut throat account for $01(0.28 \%)$ case in each followed by animal attack i.e. $02(0.57 \%)$. Deaths due to asphyxia were in $17(4.87 \%)$ cases which include hanging, strangulation and drowning cases. Deaths due electrocution, fall from height and railway track accident accounted for 08(2.29\%), 05(1.43\%) and 04(1.14\%) cases respectively. In our study deaths due to pathological disease like coronary artery disease, liver and uterine pathology accounted for 12 (3.43\%) cases. Nearly in 14 cases, cause of death could not be identified hence cause of death remains open and various sample had been preserved and sent for investigation to find out the actual cause of death. The major cause of death in males was RTA (27.22\%) followed by Burn (6.3\%) and in females, it was burn (26.93\%) followed by poisoning (5.73\%). (Table no. 3 ). 


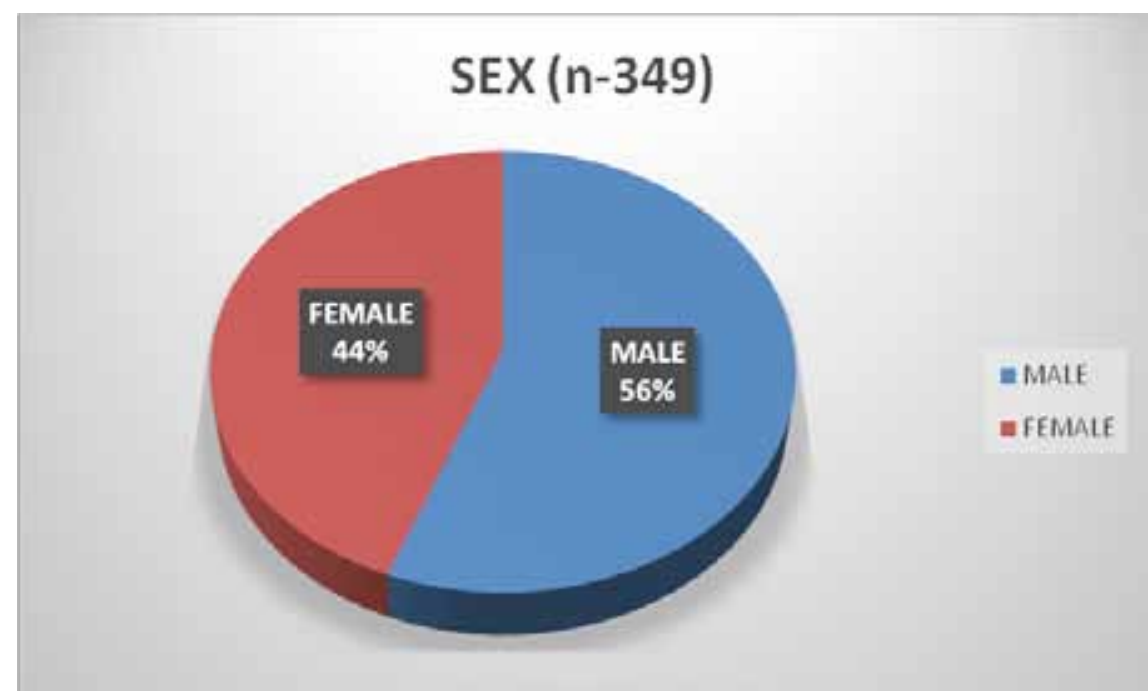

Figure-1: Sex wise distribution of Cases

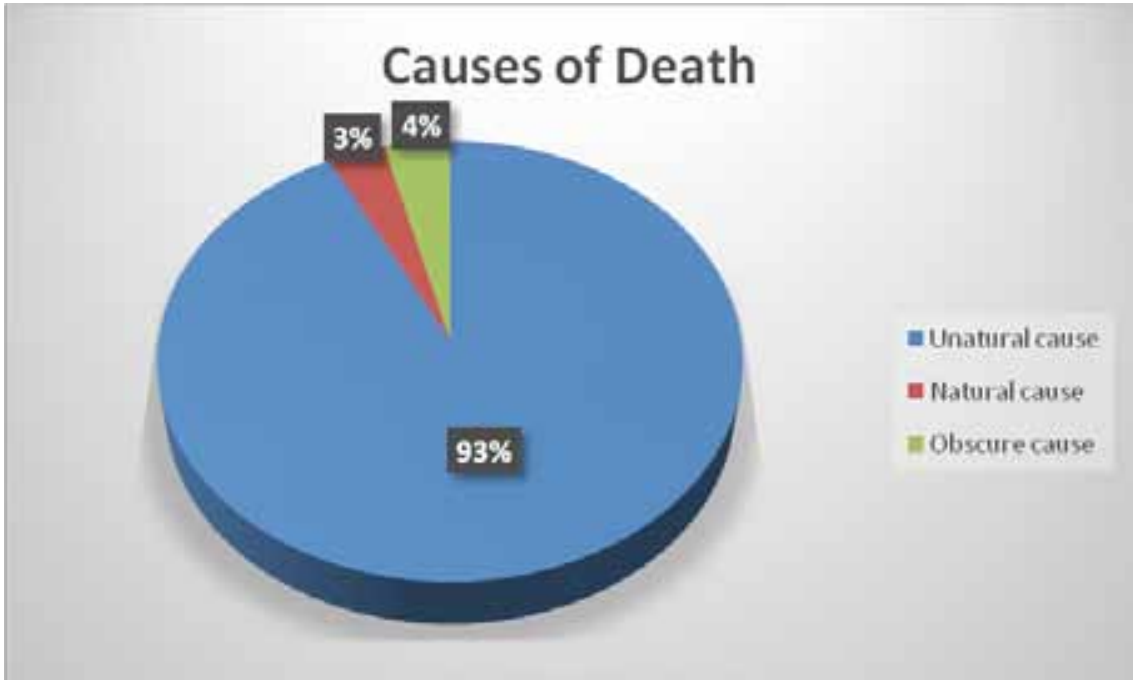

Figure-2: Distribution of the basis of Cause of Death

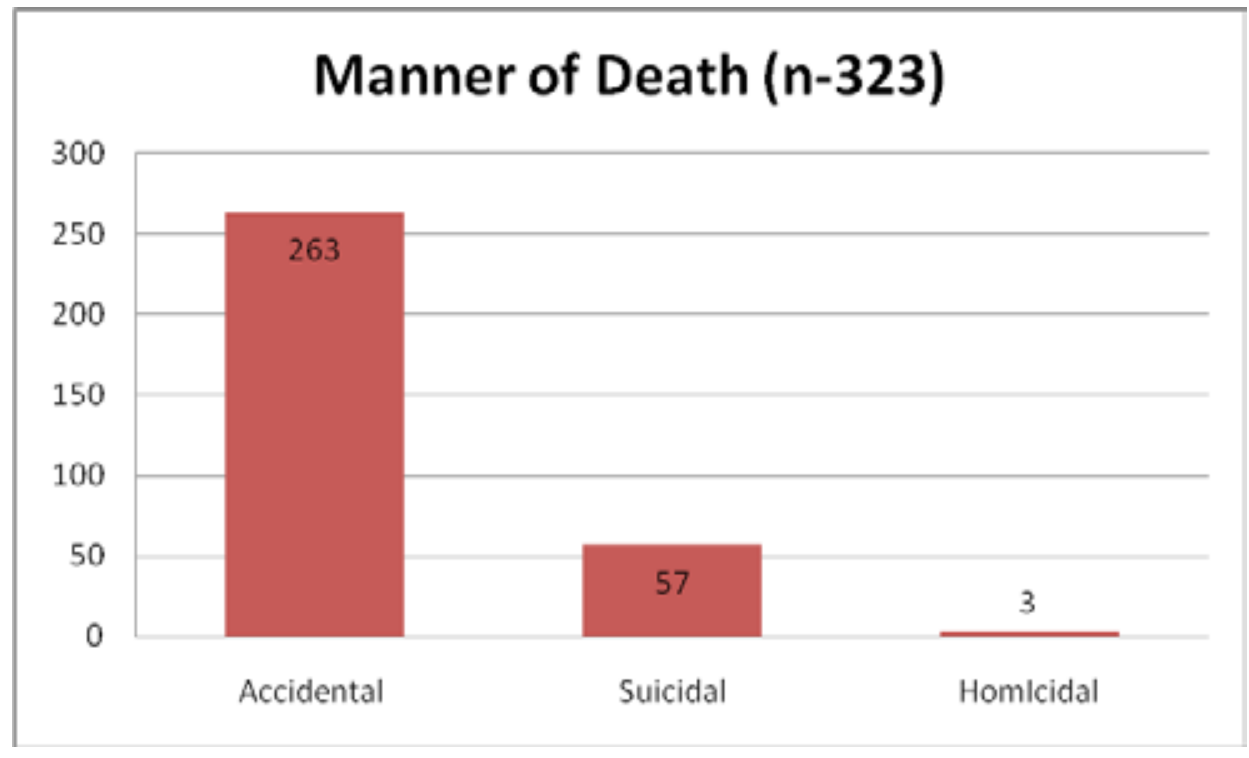

Figure-3: Distribution on the basis of Manner of Death 
Table 1: Age and sex-wise distribution of cases

\begin{tabular}{|c|c|c|c|}
\hline Age & Sex & No. of cases $(\%)$ & Total case (\%) \\
\hline \multirow{2}{*}{$0-10$} & Male & $09(2.57)$ & \multirow{2}{*}{$14(4.0)$} \\
\hline & Female & $05(1.43)$ & \\
\hline \multirow{2}{*}{$11-20$} & Male & $26(7.44)$ & \multirow{2}{*}{$60(17.2)$} \\
\hline & Female & $34(9.74)$ & \\
\hline \multirow{2}{*}{$21-30$} & Male & $64(18.33)$ & \multirow{2}{*}{$128(36.7)$} \\
\hline & Female & $64(18.33)$ & \\
\hline \multirow{2}{*}{$31-40$} & Male & $33(9.45)$ & \multirow{2}{*}{$55(15.7)$} \\
\hline & Female & $22(6.30)$ & \\
\hline \multirow{2}{*}{$41-50$} & Male & $29(8.30)$ & \multirow{2}{*}{$46(13.2)$} \\
\hline & Female & $17(4.87)$ & \\
\hline \multirow{2}{*}{$51-60$} & Male & $16(4.58)$ & \multirow{2}{*}{$22(6.3)$} \\
\hline & Female & $06(1.71)$ & \\
\hline \multirow{2}{*}{$61-70$} & Male & $12(3.43)$ & \multirow{2}{*}{$16(4.6)$} \\
\hline & Female & $04(1.14)$ & \\
\hline \multirow{2}{*}{$71-80$} & Male & $01(0.28)$ & \multirow{2}{*}{$03(0.8)$} \\
\hline & Female & $02(0.57)$ & \\
\hline \multirow{2}{*}{ Unknown } & Male & $05(1.43)$ & \multirow{2}{*}{05 (1.4) } \\
\hline & Female & 00 & \\
\hline \multicolumn{2}{|l|}{ Total } & 349 & 349 \\
\hline
\end{tabular}

Table 2: Month and sex-wise distribution of cases

\begin{tabular}{|c|c|c|c|}
\hline Month & $\operatorname{Sex}$ & Total & Total case $(\%)$ \\
\hline \multirow{2}{*}{ January } & Male & 16 & \multirow{2}{*}{$24(6.87)$} \\
\hline & Female & 08 & \\
\hline \multirow{2}{*}{ February } & Male & 20 & \multirow{2}{*}{$34(9.74)$} \\
\hline & Female & 14 & \\
\hline \multirow{2}{*}{ March } & Male & 17 & \multirow{2}{*}{$36(10.31)$} \\
\hline & Female & 19 & \\
\hline \multirow{2}{*}{ April } & Male & 24 & \multirow{2}{*}{$41(11.74)$} \\
\hline & Female & 17 & \\
\hline \multirow{2}{*}{ May } & Male & 23 & \multirow{2}{*}{$40(11.46)$} \\
\hline & Female & 17 & \\
\hline \multirow{2}{*}{ June } & Male & 14 & \multirow{2}{*}{$26(7.44)$} \\
\hline & Female & 12 & \\
\hline \multirow{2}{*}{ July } & Male & 13 & \multirow{2}{*}{$28(8.02)$} \\
\hline & Female & 15 & \\
\hline \multirow{2}{*}{ August } & Male & 23 & \multirow{2}{*}{$36(10.31)$} \\
\hline & Female & 13 & \\
\hline \multirow{2}{*}{ September } & Male & 15 & \multirow{2}{*}{$25(7.16)$} \\
\hline & Female & 10 & \\
\hline
\end{tabular}




\begin{tabular}{|l|l|c|c|}
\hline Month & Sex & Total & Total case (\%) \\
\hline \multirow{3}{*}{ October } & Male & 13 & $23(6.59)$ \\
\cline { 2 - 4 } & Female & 10 & $17(4.87)$ \\
\hline \multirow{3}{*}{ November } & Male & 06 & 11 \\
\cline { 2 - 4 } & Female & 11 & $19(5.44)$ \\
\hline Total & Male & 08 & 349 \\
\cline { 2 - 4 } & Female & 349 & \multirow{2}{*}{3} \\
\hline
\end{tabular}

Table 3: Showing distribution on the basis of Causes of Death

\begin{tabular}{|l|c|c|c|}
\hline Causes of Death & No. of Males (\%) & No. of Females (\%) & Total(\%) \\
\hline Burn & $22(6.30)$ & $94(26.93)$ & $116(33.23)$ \\
\hline RTA & $95(27.22)$ & $11(3.15)$ & $106(30.37)$ \\
\hline Poisoning & $20(5.73)$ & $20(5.73)$ & $40(11.46)$ \\
\hline Snakebite & $11(3.15)$ & $10(2.86)$ & $21(6.01)$ \\
\hline Asphyxia & $11(3.15)$ & $06(1.71)$ & $17(4.87)$ \\
\hline Pathology & $10(2.86)$ & $02(0.57)$ & $12(3.43)$ \\
\hline Electrocution & $06(1.71)$ & $02(0.57)$ & $08(2.29)$ \\
\hline Fall From Height & $03(0.85)$ & $02(0.57)$ & $05(1.43)$ \\
\hline Train Accidents & $01(0.28)$ & $03(0.85)$ & $04(1.14)$ \\
\hline Animal Attack & $02(0.57)$ & 00 & $02(0.57)$ \\
\hline Assualt & $01(0.28)$ & 00 & $01(0.28)$ \\
\hline Gunshot & $01(0.28)$ & 00 & $01(0.28)$ \\
\hline Blast Injury & $01(0.28)$ & 00 & $01(0.28)$ \\
\hline Cut Throat & $01(0.28)$ & 00 & $01(0.28)$ \\
\hline Open & $10(2.86)$ & $04(1.14)$ & $14(4.01)$ \\
\hline Total & $\mathbf{1 9 5 ( 5 5 . 9 )}$ & $\mathbf{1 5 4}(\mathbf{4 4 . 1})$ & $\mathbf{3 4 9}$ \\
\hline
\end{tabular}

\section{Discussion}

In the present study, out of total 349 autopsy cases, $195(56 \%)$ were male and 154(44\%) were female. In study by Rathod AL et $\mathrm{al}^{[1]}$ and Radhakrishna KV et al ${ }^{[6]}$ similar finding with male predominance were observed, accounted for $69.5 \%$ and $74.62 \%$ respectively. Similar finding with male predominance were also observed in other such studies. ${ }^{[2,7,8,9,10,11]}$ The reason being that as males are bread earners and females usually do house hold work, which make males more vulnerable to accidents, violence and stress. Males also indulge more in alcoholism, smoking etc than female population which make males more prone to accidents and early natural deaths.
Age group of 21-30 years showed maximum numbers of deaths among both sexes i.e. 128 (36.7\%). This finding is also consistent with the studies by Rathod $\mathrm{AL}$ et $\mathrm{al}^{[1]}$, Radhakrishna KV et $\mathrm{al}^{[6]}$ and Bhabhor $\mathrm{R}$ et $\mathrm{al}^{[7]}$ in which these age group involve 473 cases $(27.1 \%)$, 340 cases $(25.6 \%)$ and 257 cases $(24.71 \%)$ respectively. It's an adult age group which is mostly involved in most of the activities and hence more vulnerable than other age groups.

In the present study, out of total 323 unnatural deaths, most of the deaths were accidental in nature i.e. $263(75.35 \%)$ followed by suicidal deaths i.e. 57 $(17.6 \%)$ and homicidal deaths i.e. 03 (1\%). This finding is similar in the study conducted by Ramalingam $\mathrm{S}$ et 
$\mathrm{al}^{[8]}$ and Singh D et al ${ }^{[12]}$. But our findings differ from the findings observed in study conducted at Government Medical College and Hospital, Chandigarh where accidental deaths constitute $49.56 \%$, suicidal deaths constitute $38.55 \%$ and homicide deaths constitute $4.44 \%$ cases. ${ }^{[13]}$

In present study, the maximum number of deaths were due to burn (33.23\%), followed by RTA (30.37\%) and poisoning $(11.46 \%)$. This finding is similar with the study conducted by Mugadlimath A et al ${ }^{[14]}$ in which major cause of death was burn in $37.5 \%$ cases followed by RTA in $22 \%$ cases. But unlike our study, RTA was the major cause of death in study by Rathod $\mathrm{AL}$ et $\mathrm{al}^{[1]}$, Radhakrishna KV et al ${ }^{[6]}$, Bhabhor $\mathrm{R}$ et al ${ }^{[7]}$, Ramalingam $S$ et al ${ }^{[8]}$ and Atrey A et al ${ }^{[15]}$. In our study major cause of death among males was RTA account for $48.71 \%$ followed by burn i.e. in $11.28 \%$ cases, which is similar with the study conducted by Rathod AL et al ${ }^{[1]}$ and Vinay Kumar M.S. et al ${ }^{[16]}$, in which RTA among males account for $87.4 \%$ and $78 \%$. Similar finding also observed in other such studies also. ${ }^{[, 6,7,8,15,17,18,19]}$ This is due to congested and overcrowded roads with an increase in the number of vehicles and poor traffic sense leads to increased number of vehicular accidents. Major cause of death among females was burn in $61.03 \%$ cases followed by poisoning in $12.98 \%$ cases, this similar finding of burn as a major cause of death among females was also observed in the study conducted by Mugadlimath A et al ${ }^{[14]}$ and Mishra PK et al ${ }^{[20]}$. This is because they spend most of their time in kitchen and involve in the activities which required fire like cooking food, making tea, boiling water etc.

\section{Conclusion}

Our study concludes that burn was major cause of death among all deceased in Sagar region of Madhya Pradesh. So, government should work in the direction to reduce the incidence of burn by bringing out regulations to develop safer cooking appliances and educating the community especially women on safer first aid practices etc. RTA was major cause of death among males. So, traffic rule awareness program should be started, motor vehicle driving legislation must be strengthened and reinforced on time to bring down the numbers at the casualty.

Age group of 21-30 years in both males and females were most commonly involved in all death events which shows their vulnerability in meeting the death due to any cause of death. The mortality can be reduced by proper implementation of government policies and traffic rules.

\section{Conflict of Interest: Nil}

\section{Source of Funding: Self}

Ethical Clearance: It's a retrospective study and identity of the deceased is nowhere disclosed. Therefore, the approval of Institutional Ethics Committee is not required.

\section{References}

1. Rathod AL, Garg RK, Zine KV. Study of Postmortem Cases to Establish the Mortality Patterns in Aurangabad district of Marathwada Region; A Short Communication J Indian Acad Forensic Med, 2018; 40(1):17-22.

2. Joshi R, Cardona M, Iyengar S, Sukumar A, Raju CR, Raju KR. Chronic diseases now leading cause in rural India mortality data from the Andhra Pradesh rural health initiative. Int $\mathrm{J}$ Epidemiol 2006;351522-9.

3. Traffic Accidents in India 2018 [internet] http:// ncrb.gov.in. (accessed on date 05.05.2020)

4. W.H.O. Burns, 2018. Available at: https://www. who.int/news-room/fact-sheets/detail/burns/ accessed on 06 May 2020.

5. Dikshit PC. Textbook of forensic medicine and toxicology. $2^{\text {nd }}$ Edition. New Delhi PEEPEE Publishers 2014:120-121.

6. Radhakrishna KV, Makhani CS, Nikhil S, Sachin C, Sarala M, Khan RN. Profile of medicolegal autopsies conducted at tertiary medicolegal centre in southwestern India. Int $\mathbf{J}$ of Healthcare and Biomedical Research. 2015;3 (2):70-5

7. Bhabhor R, Parmar A. Profile of Medicolegal Autopsies at a Tertiary Centre in Bhavnagar Region.J Indian Acad Forensic Med, 2018; 40(4):383-86.

8. Ramalingam S, Narendar R. Profile of Medico Legal Cases which are Brought for Autopsy in the year 2015 in The Institute of Forensic Medicine, Madras Medical College, Chennai, Tamil Nadu, India - A Retrospective Study. Chettinad Health City Medical Journal 2016; 5(4): 177 - 183.

9. Bansude ME, Kachare RV, Dode CR, Kumre VM. Trends of unnatural deaths in Latur district 
of Maharashtra. J Forensic Med Sci Law 2012;21(2):1-8.

10. Varma NM, Kalele SD. Study of profile of deathsdue to poisoning in Bhavnagar region. $\mathrm{J}$ Ind AcadForen Med 2011;33(4):313-8.

11. Godale L, Mulaje S. Mortality trend and pattern in tertiary care hospital of Solapur in Maharashtra. Indian J Community Med 2013;38(1):49-52.

12. Singh D, Dewan I, Pandey AN, Tyagi S. Spectrum of unnatural fatalities in the Chandigarh zone of North-West India - A 25year autopsy study from a tertiary care hospital. J Clin Forensic Med. 2003; 10(3):145-52.

13. Sharma BR, Singh VP, Sharma R, Sumedha. Unnatural deaths in Northern India - A profile. J Indian Acad Forensic Med. 2004; 26(4):140-6.

14. Mugadlimath A, Kadagoudar S, Sheelvant S, Bambeshwar K. Profile of Medicolegal Autopsy Cases at Tertiary Care Centre in Bagalkot, Karnataka. Indian Journal of Forensic Medicine and Pathology, 2017; 10(2): 63-66
15. Atreya A, Nepal S, Gyawali PR. Spectrum of Unnatural Deaths InPalpa, Nepal: Autopsy Based Study. BJHS 2019;4(2)9: 744-749

16. Vinay Kumar MS, Ajay Kumar, Raghavendra Babu Y.P. An Autopsy Based Study on Fatal Road Traffic Accidents in Koppal. J Indian Acad Forensic Med, 2017; 39(4):375-77.

17. Katageri S, Sharma RB, Govindraju HC, Singh AK. Pattern of Injuries in Road Traffic Accidents at Chitradurga Karnataka: An Autopsy Based Study. J Indian Acad Forensic Med, 2015; 37(2):173-75.

18. Shruthi P, Venkatesh VT, Viswakanth B, Ramesh C, Sujatha PL, Dominic IR. Analysis of Fatal Road Traffic Accidents in a Metropolitian City of South India. J Indian Acad Forensic Med, 2013; 35(4):317-20.

19. Singh YN, Bairagi K, Das K. An Epidemiological Study of Road Traffic Accidents victim in Medicolegal Autopsies. J Indian Acad Forensic Med, 2005; 27(3):166-69.

20. Mishra PK, Tomar J, Sane MR, Saxena D, Yadav A. Profile of Death in Burn Cases: A Post-mortem Study. JIAFM 2016; 38(1): 8-10. 